firefighters to go fight a fire without appropriate equipment," wrote Leong.

Doctors also hold different moral values on matters such as abortion and quality of life. Does that mean physicians who come down on one side of a particular health issues are "good" doctors and those on the other side are "bad" doctors? "There is going to be some variety because we don't have a uniform definition of 'good,'" says Leong. "And the day we have a uniform definition of 'good,' that's when things get scary. Unless you are in heaven, that sounds like communism."

The quest to define professionalism isn't made any easier by the fact that, like the field of medicine itself, the definition changes over time. Attitudes have changed, for instance, about the number of hours physicians, residents in particular, should work without rest. Working fewer hours, even if it benefited your health and family life, might have been deemed unprofessional once, but many younger doctors have different views on that aspect of professionalism.

"Prior generations put a lot of emphasis on continuity of care. That was a core value of professionalism and people would spend days at work, sometimes at the expense of their own lives. Now we have a generation of doctors that see professionalism as including self-care," says Dr. Pier Bryden, a psychiatrist and the faculty lead in ethics and professionalism for undergraduate medical education at the University of Toronto. "There is a link with professionalism. People tend to not be at their best when they are sleepdeprived and physically stressed."
Still, despite the challenges of putting the evolving and somewhat esoteric concept of medical professionalism into words, many health care organizations have given it their best efforts. The American Board of Internal Medicine has its physician charter for medical professionalism, which stresses the fundamental principles of patient autonomy, primacy of patient welfare and social justice (www.abimfoundation.org /Professionalism/ /media/Files/Physician \%20Charter.ashx). The Canadian Medical Association considers the three major features of medical professionalism to be clinical independence, self-regulation and the ethic of care (http://policybase .cma.ca/dbtw-wpd/Policypdf/PD06-02 .pdf). According the CanMEDs framework, developed by the Royal College of Physicians and Surgeons of Canada, the professional role of physicians is defined as a commitment to "the health and well-being of individuals and society through ethical practice, professionled regulation, and high personal standards of behaviour" (www.royalcollege .ca/shared/documents/canmeds/the_7 _canmeds_roles_e.pdf).

Of course, many of the principles oft-mentioned in medical literature on professionalism are markedly of the motherhood and apple pie variety, generic tenets that no one would disagree with and are applicable to any profession. Good luck finding a statement of values in any professional workplace that opposes integrity, respect, reliability or any other feelgood fodder for an inspirational poster.

What has traditionally separated physicians from other professionals, however, is a strong sense of altruism. Although lip service is paid to putting the clients' needs first in the business world, it is generally accepted that the bottom line is the top priority. But medicine, many doctors would attest, is supposed to be different. The needs of the patient should always trump the financial priorities of the physician. Every skill, every decision, every morsel of scientific knowledge — all are to be used to better serve patients.

"In one sense, doctors are technicians. They are body mechanics. A lot of that involves just technical and biological know-how. But the critical part, the ethical part, is the commitment of doctors to put their technical knowledge at the service of their patients. That is the fundamental principle of the practice of medicine. The needs of the patient take precedence over your own economic practices," says Dr. Arnold Relman, professor emeritus of medicine and social medicine at Harvard Medical School in Boston, Massachusetts, and former editor in chief of the New England Journal of Medicine. "You should not be an entrepreneur. If you want to get rich, fair enough, but go into a different field. Medicine is not a place to get rich. It's a social service." — Roger Collier, CMAJ

\section{CMAJ 2012. DOI:10.1503/cmaj.109-4211}

Editor's note: Second in a multipart series on medical professionalism.

Part I: The "good doctor" discussion (www.cmaj.ca/lookup/doi/10.1503 /cmaj.109-4200).

\title{
A move toward self-medication in the United States
}

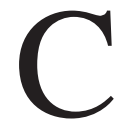

all it do-it-yourself medicine. A range of diagnostic and treatment decisions now rooted in the doctor's office will shift to patients if the United States government follows through on a proposal to sell many prescription drugs over the counter. This has set off alarm bells in some corners of health care, though others love the idea.

Supporters of the proposal argue that self-medication can be safe with certain restricted drugs if patients are given the right information and pharmacists are trained to step up in place of doctors in carefully managed circumstances. Below-the-radar maladies often go untreated, they say, because people avoid the bother, cost or stress of a doctor's appointment for conditions that could be readily relieved if more meds were available without a doctor's directive.

"I strongly believe that medicine needs to take medical care to where the patients are," says Janet Woodcock, director of the Center for Drug Evaluation and Research at the US Food and Drug Administration (FDA).

The FDA is the lead agency proposing the idea of lifting prescription restrictions on certain drugs used for diabetes, asthma, migraines, hypertension, illicitdrug overdoses and more. The agency says it would craft a list of specific phar- 
maceuticals but has not yet done so, although its federal registry notice indicated it could include epinephrine, antihypertensives and all diabetes medications (www.gpo.gov/fdsys/pkg/FR -2012-02-28/pdf/2012-4597.pdf).

To skeptics, that's like letting passengers fly the plane with flight attendants looking over their shoulder and the pilot nowhere in sight.

"Chilling and a little scary," Dr. Bobby Quentin Lanier, executive director of the American College of Allergy, Asthma and Immunology, told the FDA's hearing on the matter. "Now let me say we're not Luddites. We know change is inevitable. But we want the change to be better. And what we envision, with hearing some of the issues today, is chaos."

Over the decades, various drugs have migrated to nonprescription status and become more widely used, from fluoride to antifungals. Self-treatment advocates say many lives have been saved by making smoking-cessation aids available over the counter. They also believe treatment would reach many of the estimated seven million Americans with undiagnosed diabetes if easier pathways to drugs were established.

As envisioned by the FDA, information kiosks at pharmacies and userfriendly computer algorithms online would walk people through questionnaires helping them determine if they need a drug or should visit a doctor. Pharmacists are key players - the only health care professionals patients would need to consult in most cases. In some instances, an initial doctor's visit would be required, but not follow-ups to remain on a medication.

Robb McGory, pharmacy director at the Indian River Medical Center in Vero Beach, Florida, welcomes the initiative even if there are many unresolved ques-

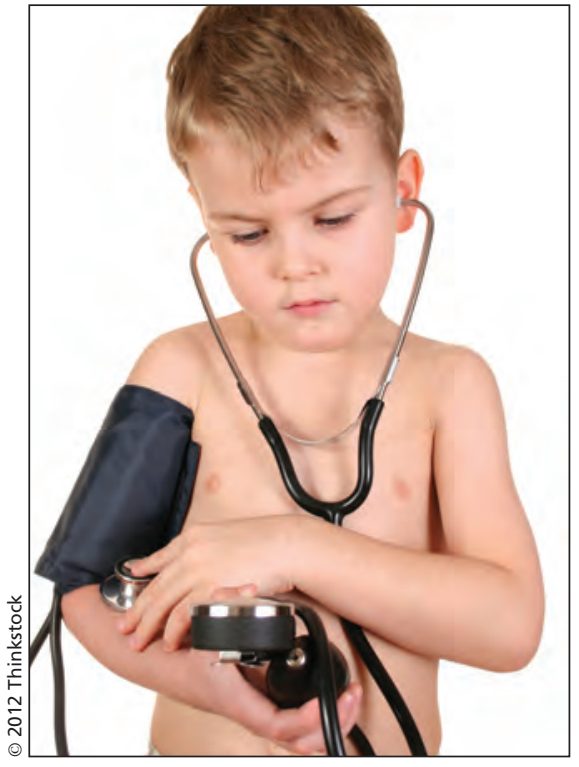

Self-diagnosis is a risky foundation on which to base the use of pharmaceuticals, critics say of the United States Food and Drug Administration's proposal to create a new category of drugs for diabetes, asthma, migraines, hypertension and other diseases.

tions about how it might unfold. "Years ago, patients started going to nursepractitioners who had diagnostic capabilities," he says. "The pharmacist is stepping into that role. We are going through a time of change, legally and professionally. We are expected to do more than fill a prescription."

Among the questions is who pays for the drugs. Both the private health insurance industry and government coverage for the elderly and the poor typically pay for prescription drugs, with other meds coming out of pocket. The new category of drugs is likely to fall into the latter group, which makes it appealing to politicians and health administrators. Cutting doctors out of some diagnoses may save the health system considerable money, shifting more costs to patients.
Dr. Richard Milsten, a urologist and member of the Indian River Medical Center Foundation board, says patients will likely diagnose themselves based solely on symptoms, without regard to other nuances that physicians utilize, such as physical appearance and examination findings.

"Patients will be right many times in their diagnosis, but I think there will be a significant error rate as well," Milsten says. "When you hear hoof beats, it is usually a horse; but every now and then it will be a raging bull. I think some patients are going to get trampled by their own misdiagnosis resulting in a delay in accurate diagnosis. This will result in prolonged suffering or worse."

With more than 30 million people expected to gain health insurance as a result of President Barack Obama's health reforms, moving some into selfdiagnosis and self-medication mode would not only reduce costs and strain on primary care facilities but, in theory, free doctors from some of the burdens of routine care and give them more time for complex cases.

But the American Medical Association isn't keen on any plan that sidelines doctors, suggesting that personalized medical information from a computer is not the same as personal care from a physician. The risks of dispensing drugs without a prescription can include a failure to detect a disease's progression or the need for changes in dosage.

Others have countered that there are dangers in the status quo which point to the need to make drugs more accessible, including the tendency for people with certain conditions, such as chronic diseases, to leave therapy at alarmingly high rates. - Cal Woodward, Washington DC

CMAJ 2012. DOI:10.1503/cmaj.109-4220

\section{Infoway to become more responsive to needs, CEO vows}

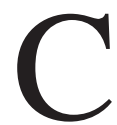
anada Health Infoway must rapidly reboot, and do so in substantial fashion, if it's to justify public outlays beyond the billions already spent on developing a national electronic health infrastructure, according to the crown corporation's CEO.
After years of defending a strategy favouring massive centralized data systems over meaningful use of electronic health data by physicians and patients, Richard Alvarez, Infoway's top mandarin, told an audience in Vancouver, British Columbia, on May 29 that the agency must reprioritize its activities - Canada's existing approach has left it lagging dismally behind international counterparts such as Australia and New Zealand in achieving health improvements through electronic technologies. 